\title{
Analysis of Passenger-Ferry Routes Using Connectivity Measures
}

\author{
Avishai (Avi) Ceder and Jenson Varghese \\ University of Auckland
}

\begin{abstract}
This study examines ferry routes that arrive at a Central Business District (CBD) during peak periods. Ferries are investigated because in certain locations they provide an alternative to buses and private vehicles, with potentially faster and more reliable journey times. The objectives of the study were to (1) conduct a connectivity analysis of existing commuter ferry services and (2) investigate potential demand for ferry services and develop potential new routes. The case study is of Auckland, New Zealand. The first stage of the study analyzed the connectivity of existing ferries routes to the $C B D$ with bus services within the $C B D$ utilizing measures of connectivity with attributes of walking, waiting, and travel times, and scheduled headways. The second stage involved developing new commuter routes from within the greater Auckland region to the $C B D$. The origins of these new routes were developed based on the potential demand of area units derived from journey-to-work data from the 2006 New Zealand Census. These new routes were then compared with existing bus routes from similar locations to the CBD to provide an additional assessment of the feasibility of the new routes. Finally, recommendations are made on the establishment of the new ferry routes.
\end{abstract}

\section{Introduction}

Ferries are an alternative to land-based modes of transportation such as buses and private vehicles, with potentially faster and more reliable journey times, as they do 
not compete for road space on congested road networks. An effective ferry service has the potential to reduce traffic congestion on roads by taking people off the road through modal shift to ferry services.

\section{Objectives}

This research study builds on previous research carried out by Ceder et al. (2009). The objectives of this study are to:

- Conduct a connectivity analysis of existing commuter ferry services.

- Investigate demand for existing ferry services.

- Develop new potential routes based on geographic feasibility and potential demand.

- Apply the methodology developed to the Auckland area and Central Business District (CBD) during the morning peak period.

\section{Background}

The Auckland CBD is New Zealand's largest employment center, with over 70,000 employees and 9,000 businesses (Auckland City Council 2006). In the Auckland region, the Auckland Regional Transport Authority (ARTA) is responsible for the coordination, planning, and funding of passenger transport. ARTA's Passenger Transport Network Plan 2006-2016 (2006) forecasts that ferry passenger trips will increase from 4.3 million to 6.6 million per year by 2016 .

The ARTA Draft Ferry Development Plan (2008) identifies key issues that will need to be addressed to ensure that the forecasted increase in patronage is served. The issues identified include the need for improved coordination of ferry route maintenance and upgrades to the Downtown Ferry Terminal, which is the destination of all commuter passenger services to the CBD.

The ARTA Sustainable Transport Plan (2007) sets out a 10-year program of scoped and costed projects and practical actions to help people make safer and more sustainable travel choices in Auckland. The plan aims to integrate sustainable transport activities with each other and with planned improvement to infrastructure and services. The sustainable transport plan identifies a significant increase in demand management activities, from the current level of around $\$ 10$ million per year to an average of $\$ 42$ million per year for the next 10 years. This investment is expected to divert 20,000 car trips each morning peak to walking, cycling, and passenger transport. 
The completion of the Central Connector busway in 2010 will result in more efficient travel between the CBD and Newmarket via key locations such as Auckland Hospital and The University of Auckland. (Auckland City Council 2009) As part of the project, there are several planned improvements to bus services, including increased frequencies, dedicated bus lanes, new bus stops and shelters, and improved traffic signals.

\section{Literature Review}

This section contains a review of papers that propose methods for optimizing the configuration of public-transport (PT) routes systems. A passenger ferry routing system has basically same characteristics as any other PT system in terms of objectives, constraints, and integration consideration. Baaj and Mahmassani (1991, 1992, 1995) developed PT network design methods based on artificial intelligence (Al). The discussed methods are based on a typical formulation of the network design problem as a programming problem with minimal frequency and load factor and fleet size constraints. The first paper (Baaj and Mahmassani 1991) gives a quantitative description, using flow charts, of a three-stage design process of a route network. In the first stage, a large set of routes is generated; the second stage involves network analysis and determination of frequencies; the third stage is network improvement. The second paper (Baaj and Mahmassani 1992) focuses on the method of representing the transportation network, using lists and arrays, in order to make the solution procedure efficient. The third paper (Baaj and Mahmassani 1995) concentrates on the stage of creating the initial set of routes, which are supposed to be modified and improved later. To generate this initial route set, a set of basic skeletons is created along the shortest paths between nodes with a high passenger demand; the skeletons are expanded using a set of node insertion manipulations.

Ramirez and Seneviratne (1996) propose two methods for route network design, under multiple objectives, using GIS. Both methods involve ascribing an impedance factor to each possible route and then choosing those that have the minimum impedance. In the first method, the impedance factor depends on passenger flow and the traveled road length. This method requires use of an assignment model. In the second method, the impedance factor depends on the number of employees who have a reasonable walking distance from the route. 
Pattanik et al. (1998) present a methodology for determining route configuration and associated frequencies using a genetic algorithm. In genetic algorithms, solutions are chosen out of a large set of possibilities in an iterative process, where the chances of a solution to survive through the iterations are higher if it yields a high value to a given fitness function. The method presented here adopts a typical programming formulation of the route network design problem, with the objective of minimizing a weighted combination of passenger time costs and operator time costs; the objective function is the basis for the calculation of the fitness function values. A methodology also is presented for the coding of variables as strings with fixed or variable length.

Soehodo and Koshi (1999) formulated a programming problem for designing PT routes and frequencies. Similar to other models, the problem is solved by first creating all feasible routes and then choosing an optimal subset. In addition to some traditional components, such as minimal frequency and fleet size constraints, the problem has some unique elements, such as the inclusion of private car user costs, transit passenger crowding costs, and transfer costs to the minimized objective function. A sub-model is developed for each of these cost types. Equilibrium of network flows is another constraint. The model assumes that demand is elastic and, therefore, the shift of passengers between different modes of transport has a major role. Both PT and non-PT demand assignment models are used.

Bielli et al. (2002) describe another method for designing a bus network using a genetic algorithm. As in other genetic algorithms, each population of solutions goes through reproduction, crossover, and mutation manipulations whose output is a new generation of solutions. In the proposed model, each iteration involves demand assignment on each network of the current set of solutions, and a calculation of performance indicators based on the assignment results. These indicators take part in a multi criteria analysis of each network, which leads to the calculation of its fitness function value.

Wan and Lo (2002) developed a network design model with an explicit consideration of intermodal and inter-route transfers. The model has two separate phases. First, the points that are to be connected with a direct service are determined in a heuristic algorithm. This algorithm uses a network representation approach named State Augmented Multi-Model (SAM), which involves inserting imaginary links to the actual road network where a direct service is provided. Afterwards, an actual bus route system is built in a mixed integer linear programming problem. 
Yan and Chen (2002) present a method for designing routes and timetables that aims to optimize the correlation between bus service supply and passenger demand. The method is based on the construction of two time-space networks: a fleet flow network and a passenger flow network. Both networks are bi-dimensional diagrams where the horizontal dimension represents bus stops and the vertical dimension represents time. While the fleet flow network shows potential activities of the bus fleet, the passenger flow network illustrates trip demand. The objective of the model is to flow buses and passengers simultaneously in both networks with a minimum cost. A mixed integer multiple commodity network flow problem and a solution algorithm, based on Lagrangean relaxation, are presented.

Tom and Mohan (2003) continued the development of genetic methods for route network design. In the current model, frequency is the variable, and thus it differs from earlier models in terms of the adopted coding scheme. While fixed string length and variable string length codings were used in previous models, the simultaneous route and frequency coding model is proposed here. The literature review presented in this section sheds light on what methodologies and quantitative methods recently were used to overcome the planning issues of PT network design. What follows is a different concept coordination-based with the idea to bridge between theory and practice.

The literature reviewed provides a spectrum of modeling approaches for publictransport network design, including the construction of ferry routes. However, none of the approaches furnishes a sound methodology for the inclusion of connectivity measures within the optimization framework. It is the purpose of this work to shed light on both the connectivity measures and consideration of realignment of ferry routes.

\section{Public-Transport Connectivity Analysis}

Connectivity analysis of PT services is made up of the following quantitative attributes (Ceder at al., 2009; Ceder, 2007):

$\mathrm{e}_{1}=$ Average walking time (for a connection)

$\mathrm{e}_{2}=$ Variance of walking time

$\mathrm{e}_{3}=$ Average waiting time (for a connection)

$\mathrm{e}_{4}=$ Variance of waiting time 
$\mathrm{e}_{5}=$ Average travel time (on a given transit mode and path)

$\mathrm{e}_{6}=$ Variance of travel time

$\mathrm{e}_{7}=$ Average scheduled headway

$\mathrm{e}_{8}=$ Variance of scheduled headway

In addition to the quantitative attributes, there are also qualitative attributes, which are not as easily measured and quantified. There are:

$\mathrm{e}_{9} \quad=$ Smoothness (ease)-of-transfer (on a given discrete scale)

$\mathrm{e}_{10}=$ Availability of easy-to-observe and easy-to-use information channels (on a given discrete scale)

$\mathrm{e}_{11}=$ Overall intra- and inter-agency connectivity satisfaction (on a given discrete scale)

These attributes contribute to an individual's preference for passenger transport of alternative modes. It is noted that each individual will have different preferences and importance (weightings) assigned to the above attributes. To determine the relative importance and weighting attributed to each of the 11 attributes, surveys need to be conducted on the preferences of passenger transport users. Such surveys were conducted by Ceder et al. (2009).

As noted above, measuring PT connectivity involves various parameters and components. Therefore, the following notations are introduced to ease the explicit construction of connectivity measures.

For a given time window (e.g., peak-hour, average week-day):

$\mathrm{O}=\{\mathrm{Oi}\}=$ set of origins $\mathrm{Oi}$

$\mathrm{D}=\{\mathrm{Du}\}=$ set of destinations $\mathrm{Du}$

$P_{D k}=\{P\}=$ set of inter-route and inter-modal paths to $D k$

$\mathrm{P}_{\mathrm{OK}}=\{\mathrm{Pi}\}=$ set of inter-route and inter-modal paths from Ok

$M_{p}=\{m\}=$ set of transit routes and modes included in path $p$

$\mathrm{E} t=\{\mathrm{e} t\}=$ set of quantitative attributes suitable for connectivity measures

$\mathrm{E} \ell=\{\mathrm{e} \ell\}=$ set of qualitative attributes suitable for connectivity measures

$\mathrm{e}_{\mathrm{mp}}^{\mathrm{j}}=$ the value of attribute ej, $\mathrm{j}=t, \ell$, related to mode $\mathrm{m}$ on path $\mathrm{p}$ 
$\alpha e=$ weight $/$ coefficient for each attribute ej, $j=t, \ell$

$\mathrm{C}_{\mathrm{p}}^{\mathrm{j}}=$ quantitative and qualitative $(j=t, \ell)$ connectivity measure of path $\mathrm{p}$

$\mathrm{Fp}=$ average number of passengers using path $\mathrm{p}$

$\mathrm{cp}(\mathrm{i}, \mathrm{j})=$ capacity (flow of passengers) of arc $(\mathrm{i}, \mathrm{j})$ between route and mode $\mathrm{i}$, and between route and mode j; each i can also be an origin Oi or destination $\mathrm{Di}$; $(\mathrm{i}, \mathrm{j})$ is contained in path $\mathrm{p}$ and is part of a network-flow model.

Based on the notations, the following equation-based notations are established:

$$
\begin{aligned}
c_{p}^{j}=\sum_{m \in M_{p}} \sum_{e^{j} \in E_{j}} \alpha_{e} e_{m p}^{j}, j=t, \ell \\
C_{D k}^{j}=\sum_{p \in P_{D k}} c_{p}^{j}, j=t, \ell \\
C_{O k}^{j}=\sum_{p \in P_{O k}} c_{p}^{j}, j=t, \ell \\
C_{D}^{j}=\sum_{D_{k} \in D} c_{D k}^{j}, j=t, \ell \\
C_{O}^{j}=\sum_{O_{k} \in O} c_{O k}^{j}, j=t, \ell \\
c_{p}^{j F}=c_{p}^{j} \cdot F_{p}, j=t, \ell \\
C_{D k}^{j F}=\sum_{p \in P_{D k}} c_{p}^{j F}, j=t, \ell \\
C_{O k}^{j}=\sum_{p \in P_{O k}} c_{p}^{j F}, j=t, \ell \\
C_{O}^{F}=\sum_{O_{k} \in O} C_{O k}^{j F}, j=t, \ell \\
{ }_{D_{k} \in D} C_{D k}^{j F}, j=t, \ell
\end{aligned}
$$


Equation (1) has the purpose of comparing paths (chains of trips) that each have an origin and destination and may include transfers. This comparison is usually carried out when there is a change in one or more paths; otherwise, it categorizes the different paths by their access/egress connectivity quality using the evaluation tool proposed.

Equation (2) is used to compare destinations. Equations (6) and (7) have the same purposes as Equations (1) and (2), respectively, but include the consideration of passenger flow by determining of the average number of passengers exposed to the calculated level of connectivity. Equation (9) compares groups of destinations with regard to overall existing connectivity quality.

All the connectivity measures that consider passenger flows should be updated in the event of changes or improvements to schedules, routes, or services. When referring to a group of destinations (zonal-based, purpose-based), paths can have a stop at one destination and continue to others.

\section{Methodology}

\section{Connectivity Assessment}

To develop an assessment of the existing operation of commuter ferry networks to the Auckland $C B D$ during the $A M$ peak period of $7 A M$ to $9 A M$, an analysis was carried out on the connectivity of existing ferry routes to the CBD with outwardbound bus services from within the CBD. This was the first stage of the study and is outlined below.

The connectivity analysis was carried out using the following assumptions:

- The analysis incorporated the quantitative measures, while qualitative measures were excluded. These qualitative measures were ease-of-transfer, availability of information, and overall intra- and interconnectivity.

- The travel times and service headway information were based on published timetables from MAXX (see below).

- The weighting attributes used in the analysis were based on the results of Ceder et al (2009).

- The connectivity measures developed did not incorporate passenger flow and were normalized by each quantitative measure to allow for crosscomparison. 
The travel time and headway information for the specific routes was obtained from published timetable information from MAXX, the regional transport brand for Auckland managed by the Auckland Regional Transport Authority (ARTA).

The connectivity for each arc was calculated using the formula:

$$
\sum_{e^{j} \in E_{j}} \boldsymbol{\alpha}_{e} e_{m p}^{j}, \mathrm{j}=t, \ell
$$

The connectivity attributes and their calculations are outlined below.

Average Walking Time $\left(\mathrm{e}_{1}\right)$ : The walking distances between the CBD ferry terminals and the location of connecting bus stops were measured using mapping tools on Google Maps. The walking times were then calculated on an average walking speed in Auckland of 1.3 meters per second, based on the findings of the study by Opus International Consultants, "Factors Influencing Walking Speed." In the cases, where the average walking distances were unknown (such as the walking distances to ferry terminals), an estimated average walking time of 13.24 minutes (Walton 2008) was used.

Variance of Walking Time $\left(\mathrm{e}_{2}\right)$ : The variance in walking time was based on the findings of Walton (2008) for variance in walking times in Auckland and resulted in 6.5 minutes $^{2}$ for walking times to ferry terminals.

Average Waiting Time $\left(\mathrm{e}_{3}\right)$ : The average waiting time $\left(\mathrm{e}_{3}\right)$ was determined from the scheduled headway and is shown in Equation (12):

$$
W_{t}=\frac{1}{2} \cdot \bar{H} \cdot\left(1+\frac{\operatorname{Var}(H)}{\overline{H^{2}}}\right) \mathrm{j}=t, \ell
$$

where:

$\bar{H}$ is the average scheduled headway (minutes)

$\operatorname{Var}(H)$ is the variance of the scheduled headway (minutes ${ }^{2}$ )

Variance of Waiting Time $\left(\mathrm{e}_{4}\right)$ : The variance of waiting time was determined from the scheduled headway and assumes that delays (which would increase the average waiting times) are negligible. The formula for the calculation of the variance of waiting times $\left(\mathrm{e}_{4}\right)$ is: 


$$
\operatorname{Var}\left(W_{t}\right)=\frac{1}{2} \cdot \operatorname{Var}(\bar{H})
$$

Average Travel Time $\left(\mathrm{e}_{5}\right)$ : The travel times were calculated from the difference between the scheduled departure and arrival times; the average travel time was determined from all scheduled trips during the AM peak period. It is noted that the actual travel times are likely to differ from the scheduled travel times.

Variance of Travel Time $\left(\mathrm{e}_{6}\right)$ : The variance of travel time was calculated from variation (data-based) in scheduled travel times.

Average Scheduled Headway $\left(e_{7}\right)$ : The average headway was determined for each arc (data-based) of all services where the origin and destinations were consistent with their respective arcs.

Variance of Scheduled Headway $\left(e_{8}\right)$ : The variance of scheduled headway was determined by the average difference between scheduled and actual (databased) departures during the AM peak.

\section{Demand Assessment}

This section outlines the methodology used for the second stage of this study, which was to determine the locations within Auckland where new routes might be feasible. The first criterion investigated was areas of potential demand based on the premise that it would not be economically viable to develop routes in areas where there is no demand.

Census data from Statistics New Zealand were used to determine areas where there was a potential demand for ferry routes into the Auckland CBD. Journey-to-work data were generated where the destination for all trips was the Auckland CBD. The CBD area was defined by the combination of four census area units (Auckland Harbourside, Auckland Central West, Auckland Central East and Grafton West), as shown by the shaded regions of Figure 1 . 


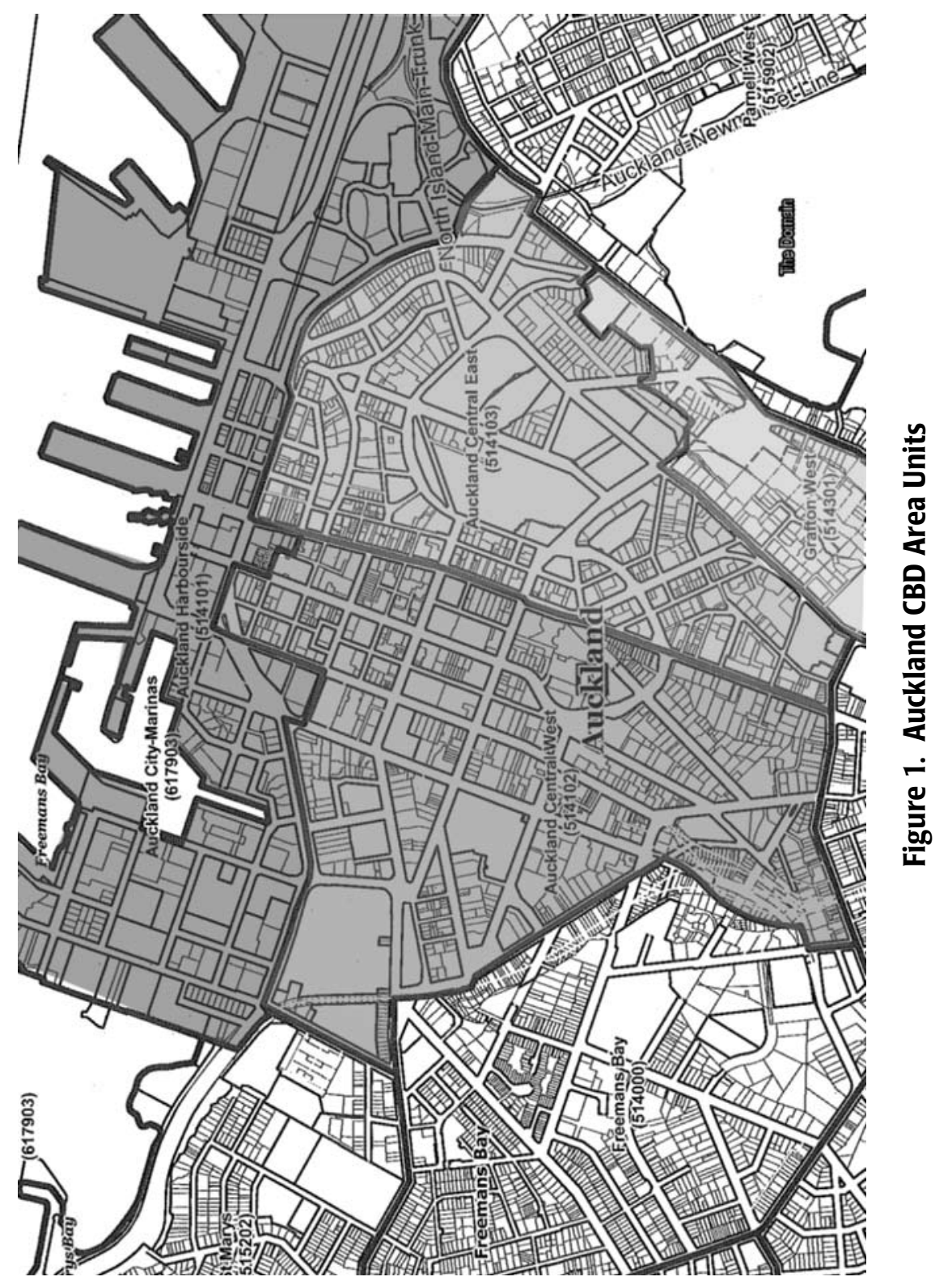


It is assumed that the majority of these journey-to-work trips were carried out in the AM peak period. In the use of the census data, the following limitations were noted.

\section{Age of Census Data}

The census was carried out on March 7, 2006, which meant that the journey-towork data were over three years old at the time this analysis was undertaken. An implication of the time lag is that economic events (such as fuel price rises) and land use and transport infrastructure changes over the past three years may have altered the region's travel patterns. This was noted and taken into account when estimating the potential demand. Investigations confirmed that all existing ferry routes were operational by 2006 , and the impacts of improvements to bus and ferry infrastructure were assumed to be negligible for the purposes of this investigation.

\section{Modes of Travel}

In the 2006 census, respondents were asked to enter their main mode of travel to work on March 7, 2006. The modes of travel indicated were:

- Drove a Private Car, Truck, or Van

- Drove a Company Car, Truck, or Van

- Passenger in a Car, Truck, Van, or Company Bus

- Public Bus

- Train

- Motorcycle or Power Cycle

- Bicycle

- Walked or Jogged

- Other

- Worked at Home

- Did Not Go To Work Today

- Not Elsewhere Included

A limitation of the census data is that journey-to-work by ferry was not included as an option for respondents to select. Discussions with Statistics New Zealand ${ }^{1}$ indicated that travel by ferry was expected to be covered under the category "Other," which also might have included travel by taxi or airplane. Statistics New Zealand 
also acknowledged the possibility that certain respondents who traveled by ferry may have selected "Not Elsewhere Included" category instead of selecting "Other." This limitation does not affect the assessment of future ferry demand, although in determining existing demand, the assumption was made that the value in the "Other" field would reflect travel by ferry for areas close to existing ferry departure points, given that all existing ferry terminals are a significant enough distance away from the CBD to make travel by taxi unlikely from a cost perspective (and travel by airplane to the $\mathrm{CBD}$ is not possible).

Another constraint with the census data was that any field that had a value of less than six (for example, five people traveling to the CBD by train from Wellington) was suppressed to ensure confidentiality of individuals. These suppressed values were treated as zero values, and it has been identified that this would result in lower demand estimates for all modes; however, given that this analysis was looking at area units (catchment areas) of high demand, it was considered acceptable that areas with potential demand less than six were ignored.

Discussions were held with Fullers Ferries Ltd., ${ }^{2}$ the main operator of ferries in the Auckland region, to determine the patronage on the existing services. Patronage information on individual routes was not available due to commercial sensitivity, although archived ARTA business reports indicate a total monthly ferry patronage of approximately 440,000 in March 2006 and 445,000 in March 2009. This captured all weekday and weekend trips, and it was not possible to accurately break down this information to obtain estimates of patronage or demand on existing ferry routes. The CBD Access Strategy 2006 identified 2,700 passengers arriving in the CBD during the AM peak (Auckland City Council 2006).

An estimation of existing demand from the census data was made based on the assumption that all trips from area units near existing ferry infrastructure under the category "Other" were ferry trips.

The estimation of the potential demand for new ferry routes was developed using census data on bus patronage. This was based on the premise that bus users would be more likely to shift modes to ferry transport if the new services provided more attractive travel times and connectivity. It is also likely that the introduction of new ferry services might result in commuters currently traveling by private vehicle to switch to ferries; however, to ensure a conservative estimation of demand only bus patronage was investigated. 
Area units with more than 10 commuters traveling by bus were identified. These area units were then filtered out based on their proximity to the ocean. As the location of any potential ferry terminal or pier would be by the sea, all area units that were more than $1,000 \mathrm{~m}$ away from the ocean were eliminated, based on the assumption that passenger transport users were willing to walk an average of 1,000 meters to a transport hub, based on the findings of Walton (2008). This eliminated any potential demand areas where passengers might drive to ferry terminals to ensure conservative demand estimation, as this is not consistent with regional policy. Once these constraints were incorporated in the evaluation, the remaining area units with high bus patronage were used to develop the potential ferry routes.

\section{Route Feasibility Assessment}

Once the areas of high demand were identified, Fullers Ferries was consulted on the feasibility of new routes to service these areas. Catchment areas that required routes traveling under bridges with unacceptably low clearances or tidal constraints were eliminated. It also was noted that some of the potential piers and wharfs investigated might require significant infrastructural investment before they would be feasible ferry terminals. As this study focuses on demand, the potential cost implications of the engineering requirements were not taken into consideration.

Once the new potential catchment areas were identified, options for new routes were developed based on estimated journey times. The journey times of these new routes were then compared with existing bus routes to provide an additional assessment of the feasibility of the new routes. The use of intermediate nodes on ferry routes also was investigated, and this was determined from estimated journey times.

\section{Auckland Case Study}

The Auckland region has the largest population in New Zealand at approximately 1.3 million. It is also one of the fastest growing regions in New Zealand, with a forecasted increase of 440,000 people over the next 15 years (ARTA 2008). This increase in population will put additional pressure on an already-congested road transport network.

This study investigated ferry routes to the Auckland CBD and their connectivity with bus services to develop an increased understanding of the effectiveness of the 
Auckland CBD as a passenger transport hub. This study also looked at new ferry routes to potentially improve the efficiency of road-based passenger transport through the creation of a mode shift from private vehicles to ferries. The initial analysis conducted benefited from the study of ferry-route design in Hong Kong by Ceder and Sarvi (2007).

\section{Ferry Operations in the Auckland Region}

There are six ferry operators in the Auckland region, with Fullers Ferries being the largest operator of commuter ferry trips to the Auckland CBD (Downtown). Table 1 presents a summary of ferry services within the Auckland region.

Table 1. Ferry Services in the Auckland Region

\begin{tabular}{|l|l|l|c|c|c|}
\hline Service & Terminals & Type & Operator & $\begin{array}{c}\text { Weekday } \\
\text { frequency } \\
\text { (trips } \\
\text { each way) }\end{array}$ & $\begin{array}{c}\text { Bus } \\
\text { Feeder }\end{array}$ \\
\hline Devonport & Downtown-Devonport & Passenger & Fullers & 31 & All trips \\
\hline Stanley Bay & Downtown-Stanley Bay & Passenger & Fullers & 8 & \\
\hline Bayswater & Downtown-Bayswater & Passenger & Fullers & 21 & All trips \\
\hline Birkenhead & $\begin{array}{l}\text { Downtown- } \\
\text { Birkenhead-Northcote }\end{array}$ & Passenger & Fullers & 24 & $\begin{array}{c}\text { Most } \\
\text { trips }\end{array}$ \\
\hline West Harbour & $\begin{array}{l}\text { Downtown-Westpark } \\
\text { Marina }\end{array}$ & Passenger & $\begin{array}{c}\text { Belaire } \\
\text { Ferries }\end{array}$ & 8 & \\
\hline Gulf Harbour & $\begin{array}{l}\text { Downtown-Gulf } \\
\text { Harbour }\end{array}$ & Passenger & $\begin{array}{c}360 \\
\text { Discovery }\end{array}$ & $2-3$ & 1 trip \\
\hline Half Moon Bay & $\begin{array}{l}\text { Downtown-Half Moon } \\
\text { Bay }\end{array}$ & Passenger & Fullers & 11 & Most \\
\hline Waiheke Passenger & Downtown-Matiatia & Passenger & Fullers & 20 & All trips \\
\hline Waiheke Vehicular & $\begin{array}{l}\text { Half Moon Bay- } \\
\text { Kennedy Pt }\end{array}$ & Vehicular & Sealink & 12 & \\
\hline Waiheke Vehicular & $\begin{array}{l}\text { Half Moon Bay- } \\
\text { Kennedy Pt }\end{array}$ & Vehicular & $\begin{array}{l}\text { Waiheke } \\
\text { Shipping }\end{array}$ & $4-7$ & \\
\hline Pine Harbour & $\begin{array}{l}\text { Downtown-Pine } \\
\text { Harbour }\end{array}$ & Passenger & Pine Harbour & 11 & \\
\hline Rangitoto & Wowntown-Rangitoto & Passenger & Fullers & 4 & \\
\hline Rakino & Pine Harbour-Rakino & Passenger & Pine Harbour & 0 (week- & \\
\hline
\end{tabular}


ARTA also identifies plans for new routes from Beach Haven and Hobsonville, with an increase in trips for the Half Moon Bay, Bayswater, Gulf Harbour, Birkenhead/ Northcote Pt, Stanley Bay and Waiheke Island routes.

\section{Data Analysis}

Existing Ferry Routes. The existing ferry routes that travel to the Auckland CBD during the AM peak are presented in Figure 2.

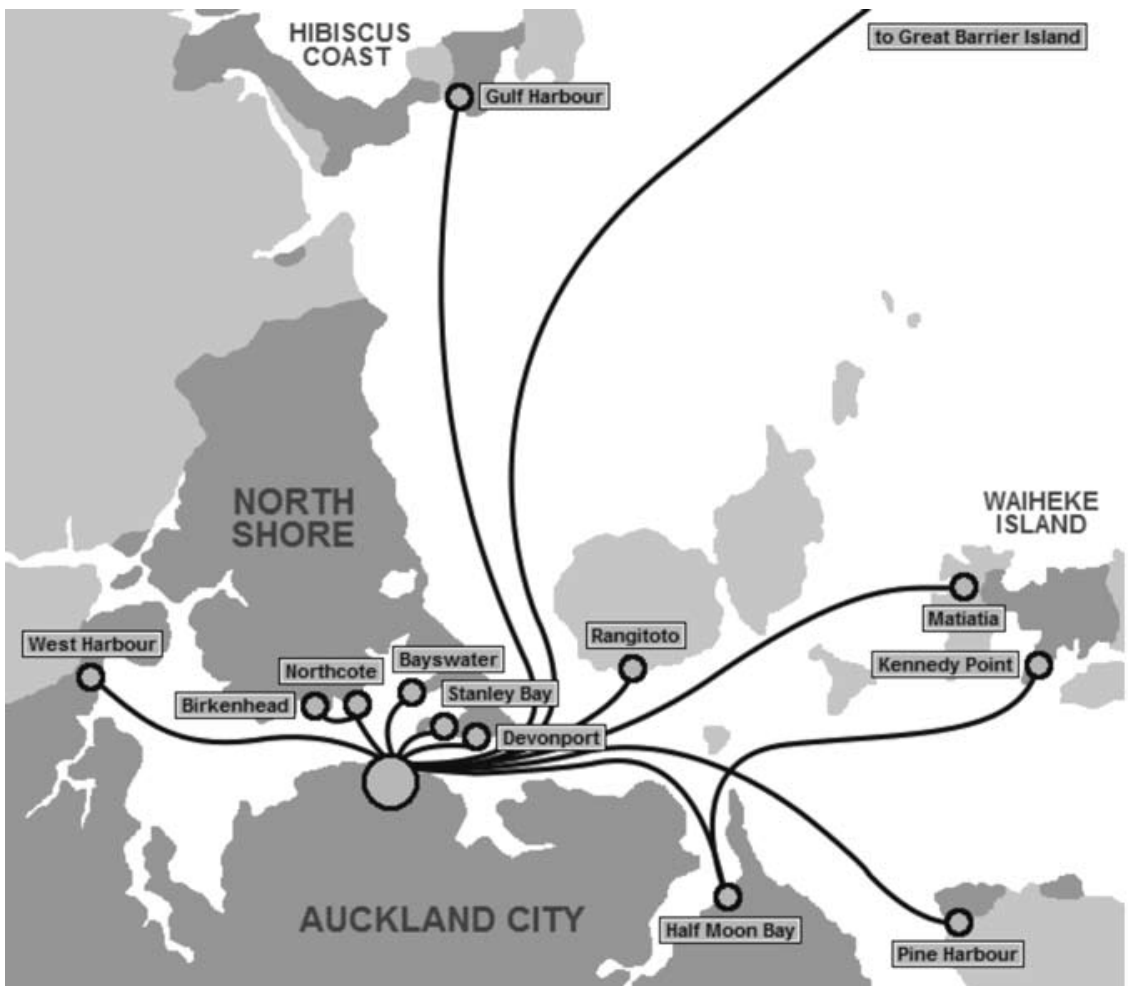

Figure 2. Map of Existing Ferry Routes in the Auckland Region (Wikipedia, 2009)

One observed characteristic of the ferry routes during the AM peak period to the Auckland $C B D$ is that they all travel directly to the CBD without any interim stops. The only exception to this is the route from Birkenhead to the CBD, which has a stop at Northcote and is executed only "on request" and does not normally occur. Consultations with Fullers Ferries confirmed that the routes were selected in this way largely to minimize travel time, as the docking procedures can increase total journey time considerably. 
From the analysis carried out, the origins of ferry trips to the CBD during the defined AM peak period were:

- West Harbour

- Birkenhead

- Bayswater

- Stanley Bay

- Devonport

- Half Moon Bay

- Matiatia (Waiheke Island)

- Gulf Harbour

- Northcote

The Pine Harbour, Rangitoto, Kennedy Point, and Great Barrier Island routes were not included, as they did include any trips during the AM peak period.

Connecting Bus Routes. The paths that were analyzed in terms of their connectivity were the ferry arcs defined above added to the arcs of bus services within the CBD.

Analysis of Census Data. The demand assessment used census data to identify regions of high numbers of residents traveling by bus. The census mesh blocks (approximately 9,800 mesh blocks for the Auckland region) were grouped into area units. This resulted in 253 area units with 6 or more residents traveling by bus, which were, in turn, grouped into regions based on Work and Income New Zealand's regional agglomerations. Table 2 shows a summary of the analysis carried out on the census journey-to-work data.

Feasibility of Catchment Areas. By analyzing Table 2, several regions and their respective area units could be eliminated as unfeasible locations for future ferry terminals. The summary of these findings is presented in Table 3, with five regions excluded from further analysis due to their geographic location or low number of commuter bus trips (less than 10). This reduced the number of feasible area units to 195. 
Table 2. Summary of Census Journey-to-Work Data

\begin{tabular}{|l|c|c|c|c|}
\hline Region & $\begin{array}{c}\text { Total } \\
\text { Employed }\end{array}$ & $\begin{array}{c}\text { Residents } \\
\text { Traveling } \\
\text { by Bus }\end{array}$ & $\begin{array}{c}\text { Proportion of } \\
\text { Bus Patrons of } \\
\text { Total Population }\end{array}$ & $\begin{array}{c}\text { Total Bus } \\
\text { Commuters in } \\
\text { Auckland }\end{array}$ \\
\hline Auckland City & 20,493 & 3,390 & $17 \%$ & $29.4 \%$ \\
\hline Takapuna & 12,414 & 2,937 & $24 \%$ & $25.5 \%$ \\
\hline Royal Oak & 7,335 & 2,082 & $28 \%$ & $18.1 \%$ \\
\hline New Lynn & 5,337 & 1,044 & $20 \%$ & $9.1 \%$ \\
\hline West Auckland & 5,106 & 666 & $13 \%$ & $5.8 \%$ \\
\hline Panmure & 3,621 & 546 & $15 \%$ & $4.7 \%$ \\
\hline Manukau/ Otara & 3,954 & 450 & $11 \%$ & $3.9 \%$ \\
\hline Orewa & 1,215 & 255 & $21 \%$ & $2.2 \%$ \\
\hline Mangere/ Otahuhu & 1,485 & 153 & $10 \%$ & $1.3 \%$ \\
\hline Papakura & 540 & 6 & $1 \%$ & $0.1 \%$ \\
\hline Manurewa & 567 & 0 & $0 \%$ & $0.0 \%$ \\
\hline Pukekohe & 249 & 0 & $0 \%$ & $0.0 \%$ \\
\hline Total & $\mathbf{6 2 , 3 1 6}$ & $\mathbf{1 1 , 5 2 9}$ & $\mathbf{1 6 0 \%}$ & \\
\hline
\end{tabular}

Table 3. Summary of Preliminary Initial Feasibility Assessment

\begin{tabular}{|l|c|l|}
\hline Region & $\begin{array}{c}\text { Possible Loca- } \\
\text { tion for Future } \\
\text { Ferry Terminals? }\end{array}$ & \multicolumn{1}{|c|}{ Reason for Exclusion (If Not Possible) } \\
\hline Auckland City & Yes & \\
\hline Takapuna & Yes & \\
\hline Royal Oak & No & $\begin{array}{l}\text { Geographic location (ferry route to Auckland CBD must } \\
\text { travel around North Island, a distance of 700+ km) }\end{array}$ \\
\hline New Lynn & Yes & \\
\hline West Auckland & Yes & \\
\hline Panmure & Yes & $\begin{array}{l}\text { Geographic location (ferry route to Auckland CBD must } \\
\text { travel around North Island, a distance of 700+ km) }\end{array}$ \\
\hline $\begin{array}{l}\text { Manukau/ } \\
\text { Otara }\end{array}$ & No & \\
\hline Orewa & Yes & \\
\hline $\begin{array}{l}\text { Mangere/ } \\
\text { Otahuhu }\end{array}$ & Yes & Low bus patronage \\
\hline Papakura & No & Low bus patronage \\
\hline Manurewa & No & Low bus patronage \\
\hline Pukekohe & No & \\
\hline
\end{tabular}


Analysis of Existing Ferry Demand. Analysis was carried out on areas near the existing ferry terminals to assess the existing ferry catchment areas and identify proportions of ferry users relative to bus users. This is summarized in Table 4.

\section{Table 4. Estimated Bus and Ferry Patronage of Existing Ferry Catchment Areas}

\begin{tabular}{|l|c|c|c|c|c|c|}
\hline Route Origin & $\begin{array}{c}\text { Public } \\
\text { Bus }\end{array}$ & $\begin{array}{c}\text { "Public Bus" } \\
\text { Trips as \% } \\
\text { of Total } \\
\text { Employed }\end{array}$ & $\begin{array}{c}\text { Other } \\
\text { (Assumed } \\
\text { to be Ferry } \\
\text { Trips) }\end{array}$ & $\begin{array}{c}\text { "Other" } \\
\text { Trips as \% } \\
\text { of Total } \\
\text { Employed }\end{array}$ & $\begin{array}{c}\text { Not } \\
\text { Elsewhere } \\
\text { Included }\end{array}$ & $\begin{array}{c}\text { Total } \\
\text { Employed } \\
\text { (in CBD) }\end{array}$ \\
\hline $\begin{array}{l}\text { Waiheke } \\
\text { Island }\end{array}$ & 0 & $0 \%$ & 237 & $67 \%$ & 69 & 354 \\
\hline Stanley Bay & 0 & $0 \%$ & 105 & $51 \%$ & 39 & 207 \\
\hline Devonport & 0 & $0 \%$ & 288 & $52 \%$ & 93 & 558 \\
\hline Bayswater & 153 & $13 \%$ & 303 & $26 \%$ & 120 & 1,149 \\
\hline Birkenhead & 456 & $23 \%$ & 195 & $10 \%$ & 66 & 1,995 \\
\hline Northcote & 219 & $27 \%$ & 51 & $6 \%$ & 27 & 798 \\
\hline $\begin{array}{l}\text { Half Moon } \\
\text { Bay }\end{array}$ & 147 & $13 \%$ & 147 & $13 \%$ & 27 & 1,110 \\
\hline Gulf Harbour & 168 & $9 \%$ & 69 & $4 \%$ & 42 & 1,806 \\
\hline West Harbour & 54 & $10 \%$ & 30 & $5 \%$ & 9 & 549 \\
\hline Total & $\mathbf{1 , 1 9 7}$ & $\mathbf{1 4 \%}$ & $\mathbf{1 , 4 2 5}$ & $\mathbf{1 7 \%}$ & $\mathbf{4 9 2}$ & $\mathbf{8 , 5 2 6}$ \\
\hline
\end{tabular}

The high proportion of journey-to-work trips to the CBD from Waiheke Island is expected because there is no alternative mode of transport to the CBD from the island. It is noted that approximately 20 percent of commuters from Waiheke Island selected the option "Not Elsewhere Included," which indicates a limitation in the use of the census data for the purposes of demand estimation.

Stanley Bay and Devonport operators also have a high proportion of CBD commuters traveling by ferry, with no commuters traveling by bus from these identified catchment areas. This attributed to the difference in journey times where Stanley Bay and Devonport have scheduled ferry travel times to the CBD of 10 and $15 \mathrm{~min}$ utes, respectively, while a similar journey by bus from either location would take at least 45 minutes with one transfer, according to bus schedules. West Harbour has the lowest number of commuter trips by Ferry at 30, according to the results of the census data analysis. 
If Waiheke Island is excluded from the above analysis (because there is no alternative to traveling by ferry), then there is an even proportion of commuters traveling to the $\mathrm{CBD}$ by bus and ferry.

\section{Analysis of Potential Future Routes}

After eliminating these regions, the number of feasible area units was reduced to 195 area units. After grouping area units by their geographic locations, the following catchment areas were developed, and the estimated modal patronage of each catchment area was obtained, based of the findings of an equal mode share between buses and ferries in areas of existing ferry patronage, as shown in Table 5.

\section{Table 5. Estimated Ferry Patronage}

\begin{tabular}{|l|c|c|c|}
\hline \multirow{2}{*}{ Future Catchment Areas } & $\begin{array}{c}\text { Existing Situation } \\
\text { (2006 Census) }\end{array}$ & \multicolumn{2}{|c|}{$\begin{array}{c}\text { After the Addition of } \\
\text { Proposed Ferry Routes }\end{array}$} \\
\cline { 2 - 4 } & $\begin{array}{c}\text { Bus } \\
\text { Patronage }\end{array}$ & $\begin{array}{c}\text { Estimated Ferry } \\
\text { Patronage }\end{array}$ & $\begin{array}{c}\text { Estimated Bus } \\
\text { Patronage }\end{array}$ \\
\hline City West & 540 & 270 & 270 \\
\hline Mission Bay & 282 & 141 & 141 \\
\hline Orewa North & 132 & 66 & 66 \\
\hline Panmure & 150 & 75 & 75 \\
\hline Takapuna & 462 & 231 & 231 \\
\hline West Auckland & 27 & 14 & 13 \\
\hline West Auckland (Te Atatu) & 111 & 56 & 55 \\
\hline City West & 540 & 270 & 270 \\
\hline Mission Bay & 282 & 141 & 141 \\
\hline Orewa North & 132 & 66 & 66 \\
\hline
\end{tabular}

It is noted that from the above analysis, the number of potential ferry users from West Auckland is lower than what was calculated for existing ferry catchments; however, this has been identified by ARTA for a future ferry route.

Results

\section{Connectivity}

The results of the connectivity analysis are presented in Figure 3 in normalized connectivity values of paths from ferry terminals to major locations in the CBD. The arcs that originate from Matiatia (Waiheke Island) present the highest normalized connectivity compared with arcs from other ferry routes to the same locations. 


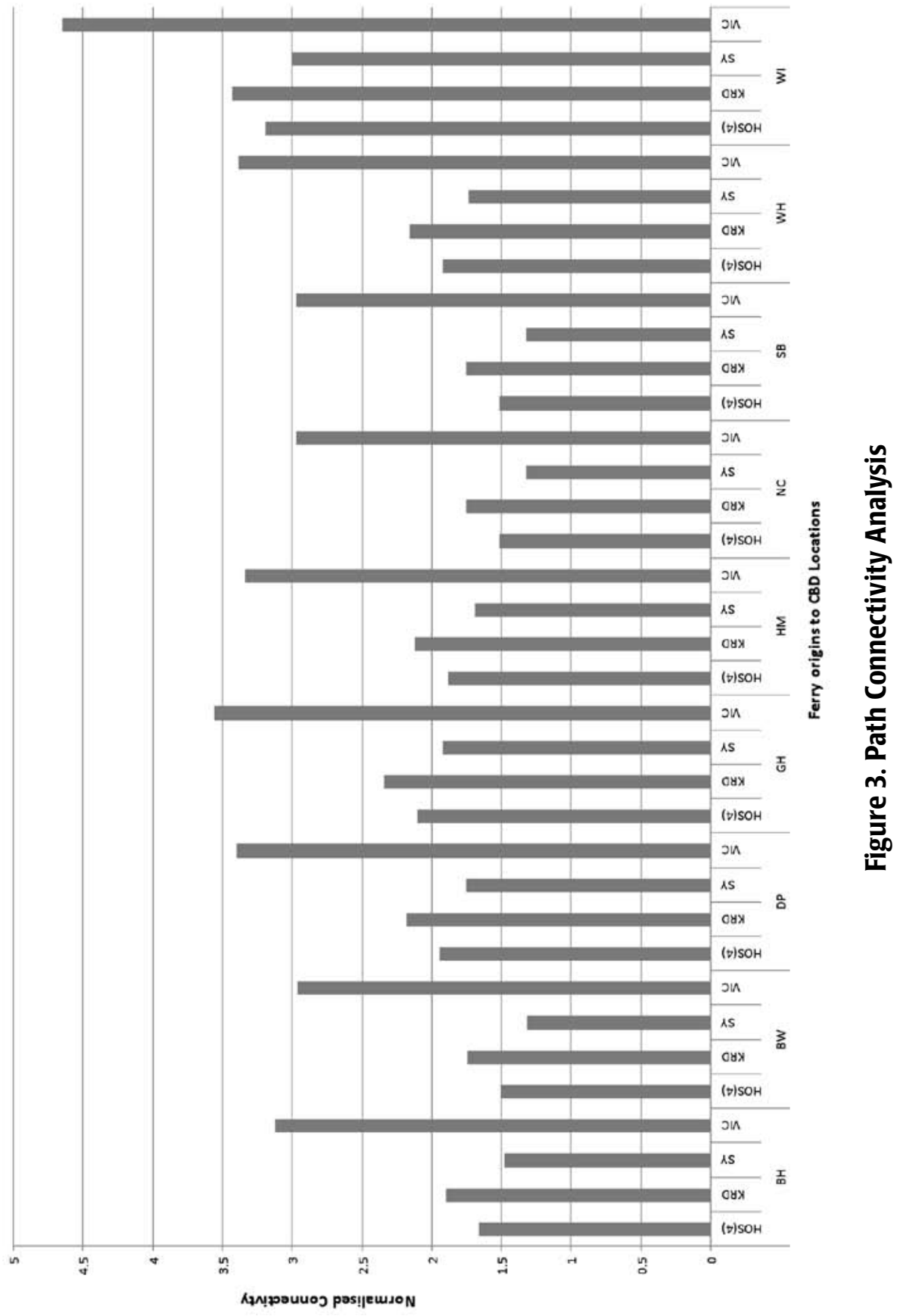


This is a result of the higher variance in scheduled headways than other ferry routes.

The destination with the highest normalized connectivity value is Victoria Park, as this has the highest variance of scheduled headway and the highest average travel time of all analyzed bus routes within the CBD.

\section{New Route Recommendations}

From the geographic feasibility and demand estimations assessments, the following routes were identified as possible ferry routes (for ferry trips into the Auckland $(B D)$, as shown in Figure 4 by the dotted line.

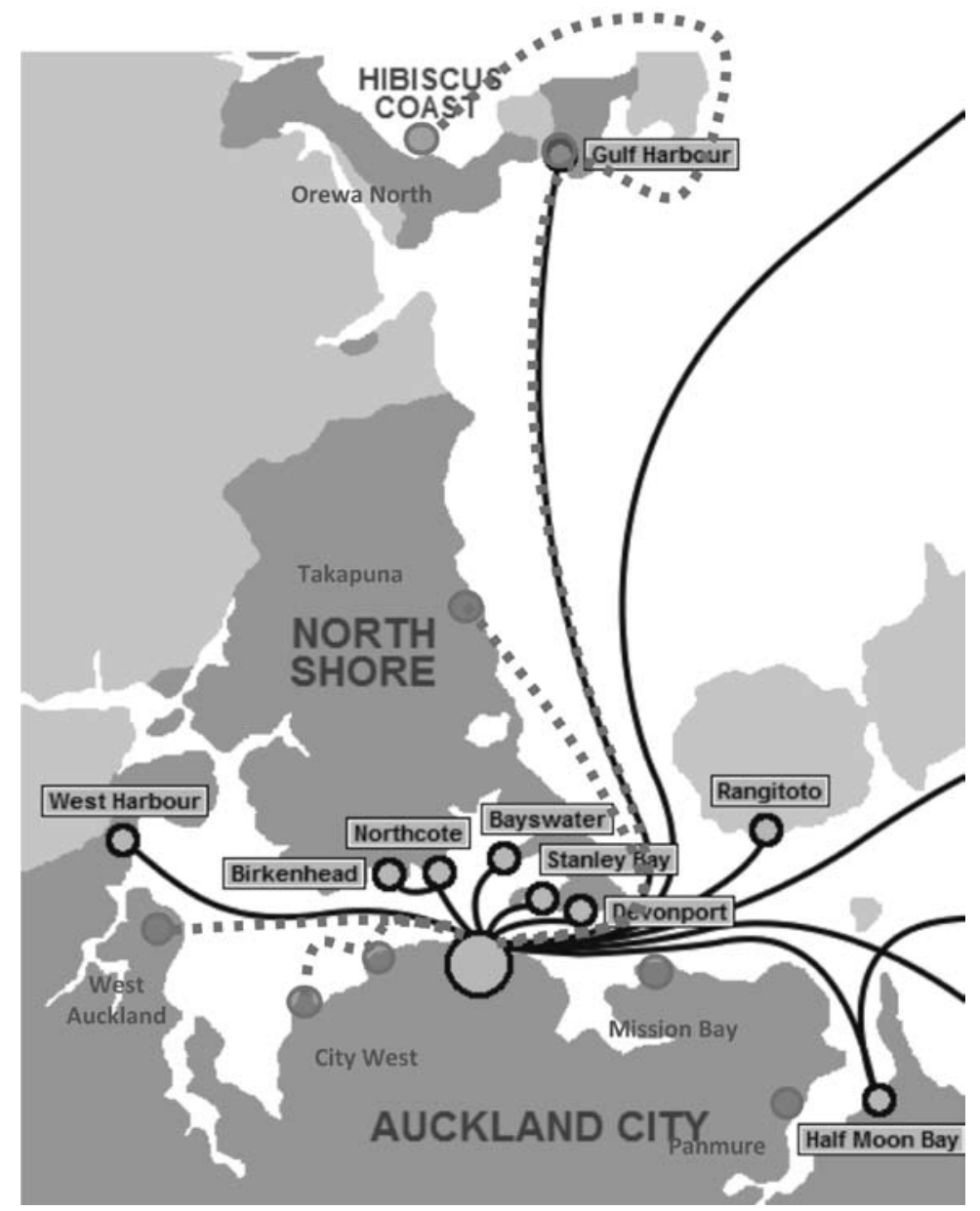

Figure 4. Potential Ferry Routes 


\section{Summary, Future Study and Recommendations}

\section{Connectivity Analysis}

This research investigated the connectivity of ferries with bus routes in the Auckland CBD and can serve as a tool and analytical framework for any ferry-related connectivity and routing study. The next step to progress the analysis of passenger transport connectivity within the Auckland would be the inclusion of rail services and the extension of all bus and rail services beyond the Auckland CBD region.

Auckland is currently undergoing significant passenger transport infrastructure upgrades, particularly with bus and rail trips to and from the CBD. On completion of these upgrades, current scheduled services will change significantly (new journey times, frequencies, and routes), and it is recommended that the connectivity assessments then be updated to capture these changes.

\section{Demand Estimation}

The approach of using existing bus commuters provided an initial estimate of the potential patronage if new ferry routes were to be established. However, to develop a more detailed estimate of the potential demand for new ferry routes, several other factors may need to be taken into consideration. These factors include ferry fares, bus fares, journey times by car, and socio-economic statistics of the catchment area, such as median incomes and private vehicle ownership, among others. One potential area for future research is the development of a probability logit model to incorporate the impact these factors have on potential ferry patronage and to provide estimates on mode shifts from other modes of transport (bus, car and train).

The census data used in this analysis were over three years old, and this research has already identified potential flaws with the use of census data (such as there was no field for ferry commuters), which contributes to limitations in the demand estimation process. Further investigation into additional sources of patronage information such as ferry passenger and occupancy surveys would provide independent data that could be cross-checked against the census information.

The development of new passenger transport routes is sometimes the result of political decisions or in preparation for expected increases in land use development or population growth. These factors have not been considered in the demand analysis but may need to be considered in future demand estimation work. 


\section{Geospatial Analysis}

The analysis of ferry catchment areas and ferry routes into the CBD involved a level of manual analysis of area units, geographic locations, and distances. This has a higher degree of error than potentially linking this directly with New Zealand statistics GIS database or carrying out more sophisticated geospatial analysis such as isochrones.

\section{Financial Feasibility}

Because the ferry services in Auckland are commercially operated, a detailed financial feasibility analysis should be implemented before any new routes would be recommended. This would involve detailed demand estimation, determination of appropriate fares, an evaluation of the expected operational costs, and determining the level of capital investment required (in terms of wharf infrastructure and procurement of new vessels). Once decisions are made on the number and types of vessels to be purchased for the new routes, it would be possible to develop an expected timetable for these new routes, which could then be incorporated back into the connectivity analysis.

\section{Recommendations}

This study conducted an analysis of existing ferry services to the Auckland CBD and their connectivity with bus services in the $C B D$ during the $A M$ peak period of 7AM to 9AM. This investigation can serve as an analytical framework for any ferryrelated connectivity and routing study. The study examined demand for existing ferry services using 2006 census journey-to-work data from Statistics New Zealand and identified new potential routes based on areas of high potential demand and feasible geographic locations.

Following are recommendations for further analysis:

1. The connectivity analysis be updated on completion of the Central Connector busway, which will significantly change the connectivity in the Auckland CBD.

2. A potential mode shift should be investigated and financial feasibility of the proposed new routes determined to gain a better understanding of the benefits of the development of new routes. 


\section{Endnotes}

${ }^{1}$ Personal communication, May 21, 2009, Statistics New Zealand Client Servicing Team Leader.

${ }^{2}$ Personal communication, May 25, 2009, Fullers Ferries Operations Manager.

\section{References}

Auckland Regional Transport Authority (ARTA). 2006. Auckland Passenger Transport Network Plan 2006-2016, ARTA Report.

Auckland City Council. 2006. Central Access Strategy, Auckland City Council Report.

Auckland Regional Transport Authority (ARTA). 2007. Sustainable Transport Plan 2006-2016, ARTA Report.

Auckland Regional Transport Authority (ARTA). 2008 . Draft Ferry Development Plan, ARTA Report.

Auckland City Council. 2009. Central Connector, http://www.aucklandcity.govt.nz/ auckland/Transport/ctc/default.asp, accessed June 17, 2009.

Baaj, M. H., and H. S. Mahmassani. 1991. An Al-based approach for transit route system planning and design. Journal of Advanced Transportation 25: 187-210.

Baaj, M. H., and H. S. Mahmassani. 1992. Artificial intelligence-based system representation and search procedures for transit route network design. Transportation Research Record 1358: 67-70.

Baaj, M. H., and H. S . Mahmassani. 1995. Hybrid route generation heuristic algorithm for the design of transit network. Transportation Research 3C: 31-50.

Bielli, M., M. Caramia, and P. Carotenuto. 2002. Genetic algorithms in bus network optimization. Transportation Research 10C: 19-34.

Ceder, A., and M. Sarvi. 2007. Design and evaluation of passenger ferry routes. Journal of Public Transportation 10(1): 59-79.

Ceder, A. 2007. Public Transit Planning and Operation: Theory, Modeling and Practice. Elsevier, Butterworth-Heinemann, Oxford, UK. 
Ceder, A., Y. Le, Y. Net, and C. Coriat. 2009. Measuring public transport connectivity performance applied in Auckland, New Zealand. Transportation Research Record 2111: 138-147, 2009.

Pattnaik, S. B., S. Mohan, S. and V.M. Tom. 1998. Urban bus transit route network design using genetic algorithm. Journal of Transportation Engineering 124: 368375.

Ramirez, A. I., and P. N. Seneviratne. 1996. Transit route design applications using geographic information systems. Transportation Research Record 1557: 10-14.

Soehodo, S., and M. Koshi. 1999. Design of public transit network in urban area with elastic demand. Journal of Advanced Transportation 33: 335-369.

Tom, V. M., and S. Mohan. 2003. Transit route network design using frequency coded genetic algorithm. Journal of Transportation Engineering 129: 186-195.

Walton, D. 2008. Impediments to walking as a mode choice. Land Transport New Zealand Research Report 329.

Wan, Q. K., and H. K. Lo. 2002. Two-phase transit network design in an integrated transit system. Advanced Modeling for Transit Operations and Service Planning - Workshop Proceedings, Crusher Advanced Study Institute.

Wikipedia. 2007. Auckland Ferry Routes, http://en.wikipedia.org/wiki/ File:AucklandFerryRoutes.png, accessed April 10, 2009.

Yan, S., and H. L. Chen. 2002 . A scheduling model and a solution algorithm for inter-city bus carriers. Transportation Research 36A: 805-825.

\section{About the Author}

Avishal (Avi) Ceder (a.ceder@auckland.ac.nz) is Professor and Chair in Transportation in the Department of Civil and Environmental Engineering at the University of Auckland and Director of the newly-established Transportation Research Centre (TRC). He was Head of the Transportation Engineering and Geo-Information Department at the Technion and a Visiting Professor at the Massachusetts Institute of Technology, the University of California at Berkeley, and others. He was the Chief Scientist at the Israel Ministry of Transport from 1994 to 1997 and the Israel delegate to the Transport Program of the European Community. In 2007, he published the book Public Transit Planning and Operation: Theory, Modelling and Practice 
(Elsevier, Oxford, UK), which was translated into Chinese by Tsinghua Publishing Press (Beijing) in June 2010.

JENSON VARGHESE is a transportation engineer with a broad range of international and local experience in transport planning, project management, traffic modeling, procurement, and financial and economic modeling. He currently works for McCormick Rankin Cagney in Auckland, where he provides advice to public and private sector clients in areas such as transportation policy, sustainability, and economic development. He has Bachelor of Engineering (Engineering Science) and Master of Engineering Studies (Transportation) degrees from the University of Auckland and a Diploma in Economics from the University of the South Pacific. 